\title{
The quest for myriad strains
}

\author{
Luca Cossettini
}

\begin{abstract}
In the era in which the web is fully demonstrating its archival potential, more and more composers make use of sound, melody and computer library repositories. It is a clear trend in popular music, which is increasingly being extended also to 'academic' composition: today authors can access and contribute to a vast array of audio materials, of procedures and languages, where historicity and innovation coexist in an eternal present. At first glance it may seem a revolution. However, a closer look reveals ancient roots in the history of music that audio reproduction has made only more evident: the fixation of music on tape, at first, has led some composers (e.g. Bruno Maderna) to create sound libraries to be reused in different works, thus blurring the borders of the Opera; later on, the dematerialization and atomization of procedures in IT have pushed towards a philosophy of sharing (e.g. libraries for Computer Assisted Composition systems) - exalted today by the capillarity of the lightning-fast web distribution - raising deep questions about the concept of author itself. Moving further backwards, to the re-uses in Rossini and Mozart, or to the anonymous formulas in Gregorian chant, could we not find the recurrence of a quest for that world of «myriad strains that once shall sound», where the composer can stretch forth a hand for a musical idea, so wonderfully glimpsed by Busoni in his Sketch for a New Esthetic of Music?
\end{abstract}

Keywords: Electronic music, Music Creativity; Music and New Technologies

Quest'opera è distribuita con licenza Creative Commons Attribuzione - Non commerciale - Non opere derivate 4.0Internazionale 


\section{Sommario}

In un'epoca in cui il web sta dimostrando pienamente il suo potenziale archivistico, sempre più compositori fanno uso di archivi di suoni, melodie, librerie informatiche. Si tratta di una tendenza molto spiccata nella popular music, ma che si sta insinuando sempre più anche nelle roccaforti della composizione accademica. Oggi gli autori hanno accesso - e contribuiscono alla creazione - di una miriade di materiali audio, di procedure e linguaggi, dove storicità e innovazione coesistono in un eterno presente. A prima vista può sembrare una rivoluzione. Tuttavia, uno sguardo più attento rivela radici antiche nella storia della musica che la riproduzione dell'audio ha reso solo più evidenti: la possibilità di fissare la musica su nastro magnetico, in un primo momento, ha portato alcuni compositori (ad esempio Bruno Maderna) a creare librerie di suoni da riutilizzare in opere diverse, facendo sfuocare così i confini dell'opera musicale; in seguito, la smaterializzazione e l'atomizzazione delle procedure, tipiche delle tecnologie dell'informazione, hanno spinto verso una 'filosofia della condivisione' (ad esempio le librerie per i sistemi di Composizione Assistita all'Elaboratore), esaltata oggi dalla capillarità e dalla fulmineità della distribuzione via web, sollevando interrogativi profondi sul concetto stesso di autore. Ma muovendosi molto più indietro, verso le pratiche di riutilizzo in Rossini e Mozart, o verso le formule anonime del canto gregoriano, non si potrebbe scorgere la ricorrenza di una ricerca di un mondo di «milioni di melodie che un giorno risuoneranno», dove il compositore può tendere una mano per un'idea musicale, meravigliosamente intravista da Busoni nel suo Abbozzo per una nuova estetica della Musica?

Parole chiave: Musica elettronica, Creatività musicale, Musica e nuove tecnologie 


\section{DJing}

It is almost 20 years by now when, at the dawn of the digital era, Paul D. Miller - aka DJ Spooky - said in an interview about his composing techniques:

the word cut makes me think about roads and highways cutting across the landscape. Flying over major urban areas you see the countryside, and then slowly it becomes more geometric, with roads carved into the land. By the time you get to Manhattan or another center, you see all these geometric stratifications, layers of cuts. The urban planner Robert Moses leveled much of the Bronx to build highway systems. He sliced through what were then different layers of class. Ghetto communities were much more affected by this road-building project than others were. That influenced how people viewed community, which affected hip-hop music. That's one kind of cut. Another kind of cut is the film cut. For the early filmmakers, such as Georges Miliès and the Lumiere brothers, editing and being able to splice film was part of how to put scenes together. Related to this was the collage culture of Pablo Picasso and the poetry of Guillaume Apollinaire, who were juxtaposing phrases and pulling random elements together to make language poems. Then there is jazz's layering and its radical juxtaposition of totally nonsequential riffs. Film cuts, literary cuts, sound cuts-each one reflected the culture itself.

In America, everybody had to collage together their identities whites, blacks, and, after a certain point, Indians because they got moved around so much and their tribes were broken up. This is the land of the blank slate, so it's a cut-and-paste culture. Now you can jump from website to website, paste together essays and sound fragments it's sampling. These issues have migrated almost fully intact to the digital age (Becker, Crawford \& Miller 2002, p. 85). 
And they surely have: today, in the era in which the web is fully demonstrating its potential, more and more composers make use of sounds (samples), melodies and computer libraries repositories. It is a clear trend in popular music (see Dannenberg, Gold, Liang \& Xia 2014 and Delfino 2017), which is increasingly being extended also to 'academic' composition: today authors can access and contribute to a universe of audio materials, procedures and languages, where historicity and innovation coexist in a kind of eternal present. The web has become a great archive that composers can use to feed their musical ideas.

It is sufficient to take a look at the main Digital Audio Workstations (DAW) used today for composing. Let's take one of the most famous: Ableton live. One of the features at the basis of its commercial success is the plenty of libraries for assisted composition. Authors can find virtual instruments, sound libraries and samples, composing assistants such as arpeggiators or riff generators. All these features can be used in studio or for live performances. At first glance it may seem a shortcut for amatorial composition. There could be enough for the more 'academic' composers and musicologist to cry fool (see Montano 2010). But if we take a closer look, we can find that there's more to the picture than a simple tool for commercial music making. For example, a Max (once Max/MSP) environment - for many years now considered a standard in computer music -, can be integrated in Ableton as a module, and it can be used for real time processing, along with samplers, synthesizers, etc. (an astounding example can be found in Brown $\&$ Britton 2014). More and more young musicians use such systems both for composing and performing, since they have access to a huge on-line archive of patches and software libraries that can be manipulated according to their composing ideas. In the very last years, also due to the Covid-19 pandemic, these practices have reached the highest level of exploitation. In addition to institutional archives that provide also audio recording (Library of Congress, Archive.org, etc...), websites dedicated to the sharing of samples and to the on-line 'co-creation' were born and had great circulation (e.g., Splice, 
Tracklib, Sampleswap). Composers use these archives as ready made tools, thus shifting the compositional process from coding from scratch back to the implementation and the exploration of instruments.

Today, musicians and musicologists are facing a global expansion of a practice already born at least 30 years ago, at the dawn of the Computer Assisted Composition (CAC): the development and the consequently sharing of patches, sounds, and libraries.

\section{Fausto Romitelli's digital 'toolbox'}

At the beginning of the $1990 \mathrm{~s}$, in the golden pioneering age of personal computer music, and especially when IRCAM (Paris) began to develop CAC systems such as Patchwork, composers and IT technicians began to write libraries, lines of code, modules that, at the time, were then shared between computer scientists and artists as tools to aid the composition procedures.

A case in point is the work of Fausto Romitelli. As Olto pointed out, already in 1991, for composing of Natura morta con fiamme, Romitelli had experimented with sound synthesis using Csound and with its control by means of LISP programming language:

in Natura morta con fiamme sounds have been obtained using Csound. Csound allows for synthesis, starting from basic operators, for example oscillators or filters, which in turn can be described by means of several parameters (start, end, amplitude and frequency envelope, phase, bandwidth etc.). To produce complex sounds it is therefore necessary to manage a large amount of data. Romitelli has overcome this difficulty by developing a control program written using LISP which he called WORKLISP: by defining specific functions, this program allows for substantial reduction of the amount of data to be manipulated, as well as for categorizing the type of sound to be obtained (Olto 2017b, p. 427) 
From 1991 to 1995 at least, this set of libraries, was stratified with new functions aimed at implementing new compositional strategies.

During his stay at IRCAM as compositeur en recherche Romitelli also worked with Patchwork, and he managed to re-use almost all the procedures he wrote since the composition of Natura morta con fiamme in the new software environment. Many works, both electronic and instrumental, had benefits from the implementation of his scripts, Entrance (1995) in particular. In fact, all the musical parameters (frequency, duration, amplitude etc.) generated and manipulated by these scripts could be translated into musical notation by means of libraries or stand-alone software such as Esquisse at first and Patchwork itself later on. The software system developed by Romitelli consists of two files: lispdef and WORKLISP. The former contains a large number of functions in LISP; the latter is instead designed to evaluate the functions defined by lispdef and to generate the orchestra files for Csound (see Olto 2017a).

In WORKLISP we can identify hundreds of different functions for at least 8 different synthesis procedures:

- $\quad$ Simple additive synthesis;

- $\quad$ Additive synthesis with formants;

- $\quad$ Subtractive synthesis from noise;

- $\quad$ Subtractive synthesis from periodical source;

- $\quad$ Filtering of a given sound;

- $\quad$ Additive synthesis with amplitude modulation;

- $\quad$ Frequency modulation;

- $\quad$ Frequency modulation with formants.

Based on the developments of CAC, Romitelli thus translated his theoretical-musical reflection into LISP programming language, then implemented in the Patchwork graphic environment.

One can find simple procedures, like creating distorted spectra, given a number of partials to be generates (part), a fundamental frequency (freq) and a distortion coefficient: 


$$
\begin{gathered}
\text { (defun dist }(\text { part freq dist }) \\
(\text { let }((\text { res })) \\
(\text { dotimes }(\mathrm{n} \text { part res }) \\
(\text { setf res }(\text { cons }(* \text { freq }(\operatorname{expt}(+\mathrm{n} 1) \text { dist })) \text { res }))) \\
(\text { reverse res })))
\end{gathered}
$$

Functions then made gradually more and more complicated, like a script for creating a group of spectra on different fundamental frequencies and different distortion coefficients, given a number of partials to be generated $(p)$, a list of fundamental frequencies (list 0$)$ and a list of distortion coefficients (list1):

$$
\begin{gathered}
\text { (defun distcord2 (p list0 list1) } \\
(\text { if }(\text { null list0)nil } \\
(\text { cons }(\text { dist } \mathrm{p}(\text { car list } 0)(\text { car list })) \\
(\text { distcord2 } \mathrm{p}(\text { cdr list } 0)(\text { cdr list } 1)))))
\end{gathered}
$$

Step by step he went further, up to more complex functions like the simulation of FM synthesis, based on the idea of harmonie fréquentielle by Tristan Murail (Murail 2004), given a carrier frequency (port) a list of modulating frequency (listmod) and a modulation index (index):

$$
\begin{aligned}
& \text { (defun fmmodplus (port listmod index) } \\
& \text { (if (null listmod) nil } \\
& \text { (cons (fm port (car listmod) index) } \\
& \text { (fmmodplus port (cdr listmod) index)))) }
\end{aligned}
$$

It is interesting to notice that these codes could be used for composing as well as for analyzing rough musical materials. This function, for example, given a fundamental frequency (fond) and the number of the partial (npart) gives back the distortion coefficient for any given frequency (freq): 
De Musica, 2021 - XXV (1)

(defun finddist (freq fond npart)

(log (/ freq fond) npart))

Each function can also be connected to another to create a complex compositional environment. For example, the aforementioned function distcord 2 calls for the basic dist function, already defined in the library; fmmodplus calls for a basic $f m$ function, and so on. We can say that through the development of original code, Romitelli created his own computer 'tool set' which combined analysis, manipulation of parameters and synthesis in a single modular environment, as well as directly conveying compositional solutions both in musical notation and sounds through the subsequent implementation of Csound synthesis (for further details please refer to Olto 2017a). The use of this tools set in different compositions reflects the development of the composer's aesthetic; its study is of paramount importance for understanding his music.

In the case of Patchwork, it was the implementation of a functional language such as LISP that made the sharing of function and libraries possible. Anyway, even long before the Internet era, sharing was an important part of the compositional process. Computers made the creation of archives of music generation procedure possible since the beginning of the experimentation in this field. It was just a problem of computational time and of interoperability that slowed down the praxis of sharing and re-using. As a matter of fact, they were already in the air in the 1960 s, connected to the creation of sound catalogues and archives.

\section{Jean-Claude Risset's catalogue}

Jean-Claude Risset's catalogue of electronic generated sounds was created in 1969 when real time was just a mirage, a pipe dream. In its written form, Risset's catalog appears as a theoretical definition of synthesis sounds to be 
created in non-real time with a computer, and then to be recorded on magnetic tape (figures 1 and 2).

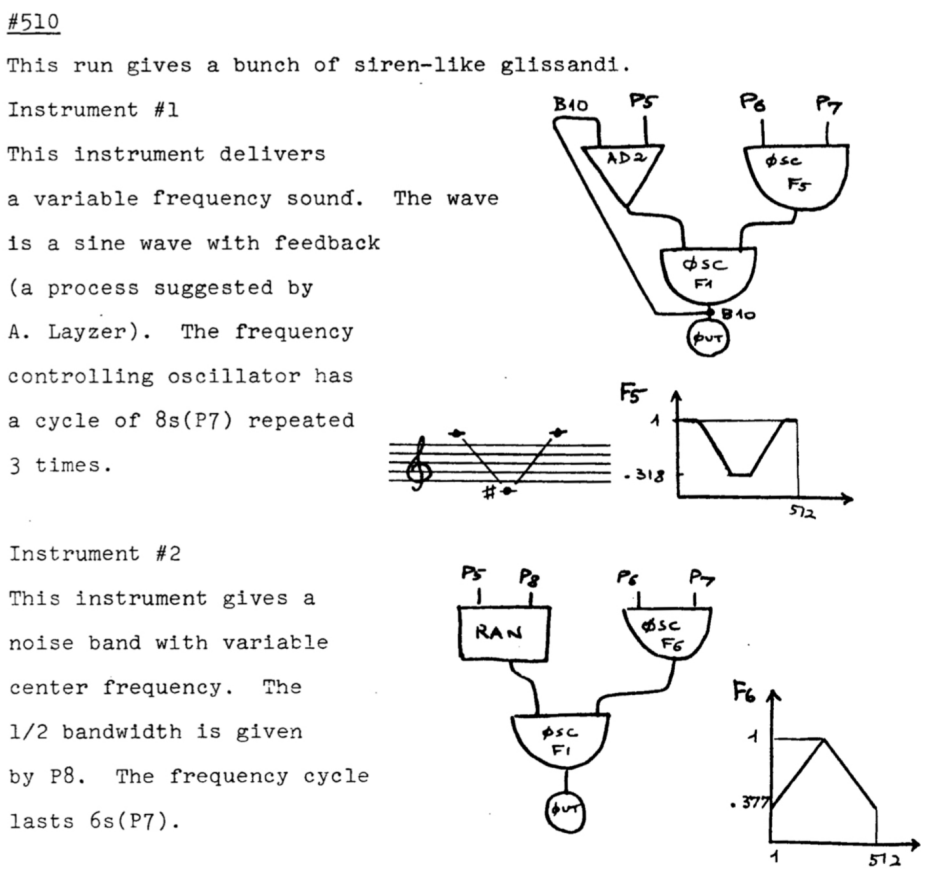

Fig. 1. Description of instrument n`510 from Risset’s catalogue (Risset, 1969: a-8 3).

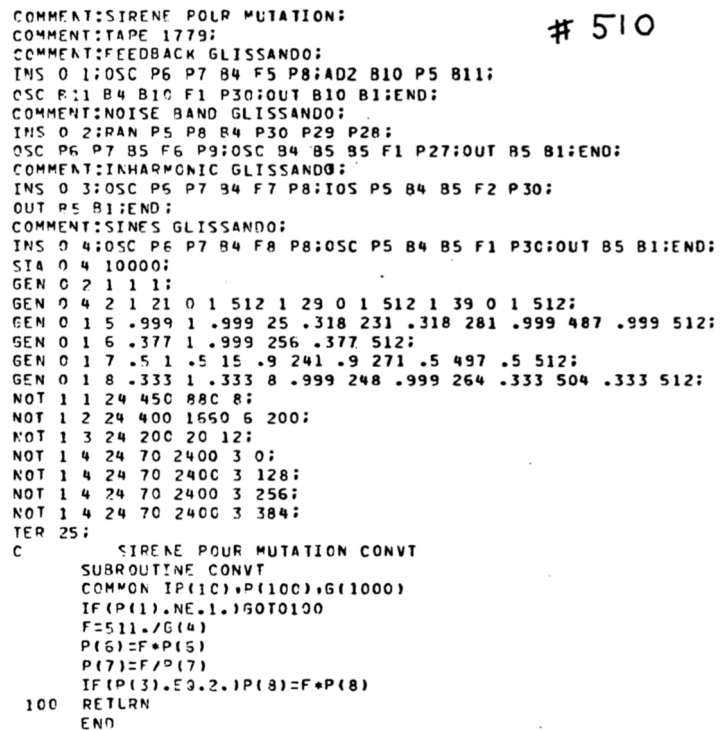

Fig. 2. Code for instrument n`510 from Risset’s catalogue (Risset 1969, p. a-85). 
The underlying idea was to create a sound library ready to be used for musical creation, without waiting hours (nights or even days) to generate every single sound. The most astonishing part of Risset's work is that, starting from the theoretical definition of synthesis procedures, he made the choice of the compiling language indifferent, thus allowing portability and the possibility of reusing sound material in the future. Reaching a higher level of abstraction, he manages to tackle obsolescence. As Risset himself pointed out:

Some of the sound recipes from my catalogue could be used by musicians doing computer synthesis with modular programs of the Music 4 - Music 5 type: Music4BF, Music 10, Music 11, Music 360, CMusic, CSound. Some have even been studied by users of analogsynthesizers such as Moog. In Marseille, Daniel Arfib has adapted Music 5 for IBM-PC compatible computers, and he had no difficulty replicating the examples of my catalogue: twenty years later, the recipes still work - as they should - and I still use some for my own musical works. For instance, I used flute-like and percussion-like sounds, as described in $n^{\circ} 100$ and 400 of the catalogue, in Passages (1982) and L'autre face (1983). I used harmonic arpeggios (as described in $\mathrm{n}^{\circ} 500$ to the 503) in [...] Contours (1983) (6'30 "to 8'57'), Sud (1985) (2'50 “to 3'40”), Voilements (1987) (6'56 “to 7'17”), Attracteurs étranges (1988), as I had done in 1968 for the beginning of Little Boy and in 1969 for Mutations (e.g. 29 “to 52", 1'28 “to 2'20”). I also used clarinet-like sounds, as described in $\mathrm{n}^{\circ} 150$, in Mutations (2'45" to 3'10") as well as in Voilements (2'21”, 2'44”, 3'08'). (Risset 1992; 2018, p. 333)

Risset's catalog has been repeatedly 'rewritten' by Risset himself, but also by other composers, who have not hesitated to use the results of his research to develop other catalogs or original music. For example, Stanley Haynes used some of his rough piano imitations (instruments No. $300 \mathrm{~d} 301$ ) to produce the tape for Prisms for piano and magnetic tape, produced at IRCAM 
in 1977. In his book Sound Structure in Music, Robert Erickson (Erickson 1975 ) reported the example $n \circ 550$ (which was an attempt to prolong the harmony in timbre). In the early 90s John Philip Gather has assembled the socalled Amsterdam Sound Catalog (Gather 1995) which includes several examples of Risset catalog transcribed for CSound as well as other sound data (see Risset 1992; 2018, p. 334).

Already in 1969 Risset foresaw the importance of creating and sharing catalogues of sounds and sound generating computer procedures: «we hope that [the catalogue] - he wrote - will stimulate other people working in the field of synthetic sound to do the same kind of presentation of their work: then one could take advantage of their results, and an extended repertory of sound would gradually build up and be made readily available» (Risset 1969; 2018, p. 330). In 1992, the perspective of a global digital era he has renewed his desire, and showed us the means for its realization:

because of the availability of the compact disc, it is today much more convenient to give to the user random access to many different examples. I consider it is very important to communicate mutually one's experiments and experiences on sound synthesis, processing and musical elaborations, so that one can take advantage of the effort of others and make the exploration of computer music a rich cooperative venture, even though the musical work remains in the end the responsibility of the individual composer (Risset 1992; 2018, p. $340)$.

\section{Maderna's dimension(s)}

Going on in our journey backwards, we can see how, even before the advent of the computer, the practice of re-use was already intrinsic to the technology of technical reproduction of sound. Like Risset, due to technical limitations of the time, was forces to create a 'tape library' at the end, many composers who wrote electronic music in the analog era before him had adopted the same 
strategy. One of the most significant example of this praxis can be found in Bruno Maderna's music, notably in the reuse of the same sound materials in different compositions. Let's take the case of Dimensioni II/Invenzione su una voce and Hyperion.

Dimensioni II/Invenzione su una voce is an electronic/mixed composition on which Bruno Maderna begun working between December 1959 and early 1960 at the RAI Studio di Fonologia Musicale in Milan. It is based on a phonetic text with no semantic meaning, drafted by Hans G. Helms, and it was designed to allow for a dialogue between the live voice of Cathy Berberian and its recorded counterpart (modified and edited by Maderna himself). A study of the audio sources carried out by MIRAGE Laboratory of the University of Udine revealed a surprising number of author's variants: the sound documents attributable to Dimensioni II/Invenzione su una voce show that an unimaginable amount of work has been done on the recordings.

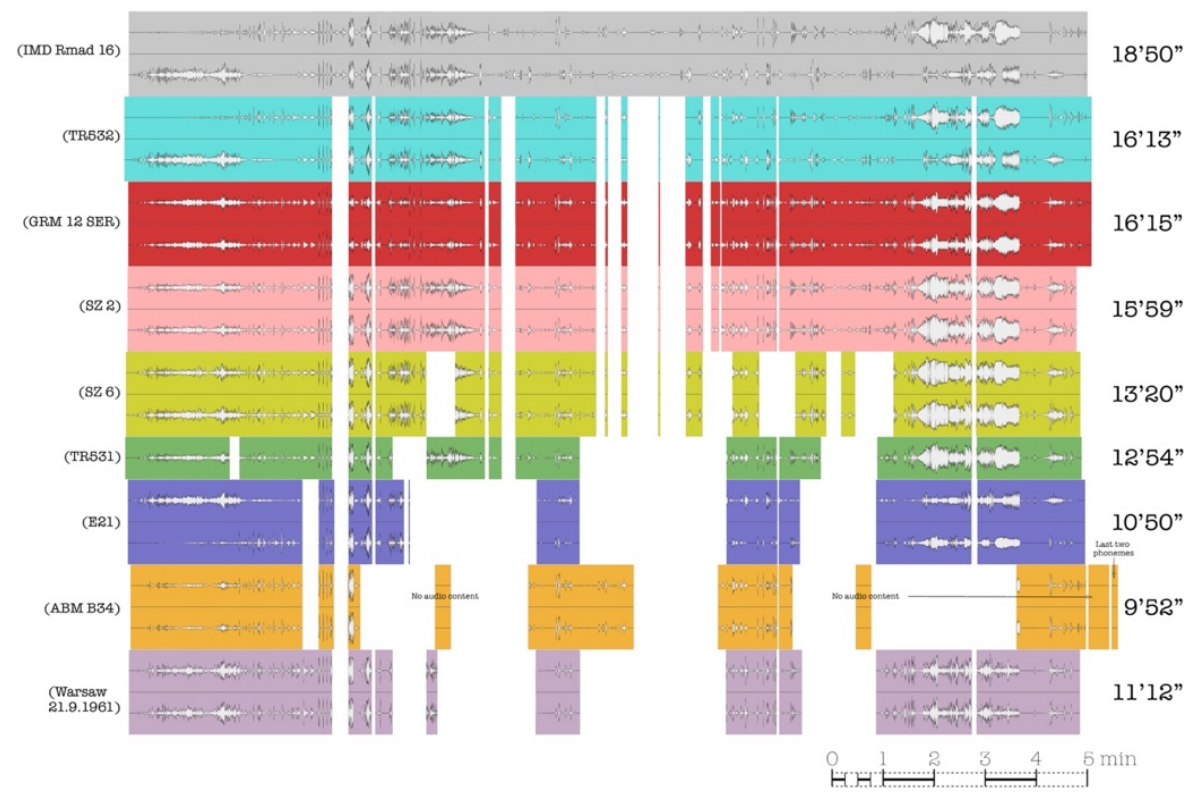

Fig. 3. Nine significant sources of Dimensioni II/Invenzione su una voce.

Figure 3 shows the comparison among nine significant sources (out of the almost 30 analyzed). Audio files, obtained by digitizing the signal contained on the original carriers, have been split at the editing point and then vertically aligned. Gaps show the material removed at any physical revision of the 
original tapes. The timeline is significant: from 1960 to 1972 Maderna devoted special attention to this work, after it was first performed. He worked on the tapes to adjust their duration to the various concert settings - also affected by the increasingly less assiduous presence of Cathy Berberian; he finally went back to parts of the composition and added them to his later works such as Hyperion, Ages, Tempo Libero.

The succession of productions of Dimensioni II / Invenzione su una voce is typical for the practice of the Venetian composer, but it is not attributable to the aesthetics of the open work (see Eco 1989), because the endless variety of production is not a result of involvement on the part of the public or of other composers, as happened for example in Scambi by Henri Pousseur, but rather of a repeated action by the author on the tape (supported by his assistant Marino Zuccheri). Thus, in Dimensioni II / Invenzione su una voce Maderna did not give up authoriality fully. Indeed, the role of the author is rather reaffirmed in the continuous revision of the work. This can be seen by analyzing the types of intervention. A version lasting $~ 19$ ' was gradually shortened by the author through subsequent cuts; a second version lasting $\sim 16$ ' (presumably created at the same time as the 19' one and designed to be performed without live voice) was transferred almost unaltered to the early 'Italian' versions of Hyperion (premiered in Venezia 1964, and in Bologna 1968 and 1972) along and then mixed with the final part of Le Rire (figure $4)$; different mixing and recombination procedures, on the other hand, can be found in Hyperion en het geweld, in Ages and most notably in Tempo Libero where the sound materials undergo an extreme fragmentation process. 


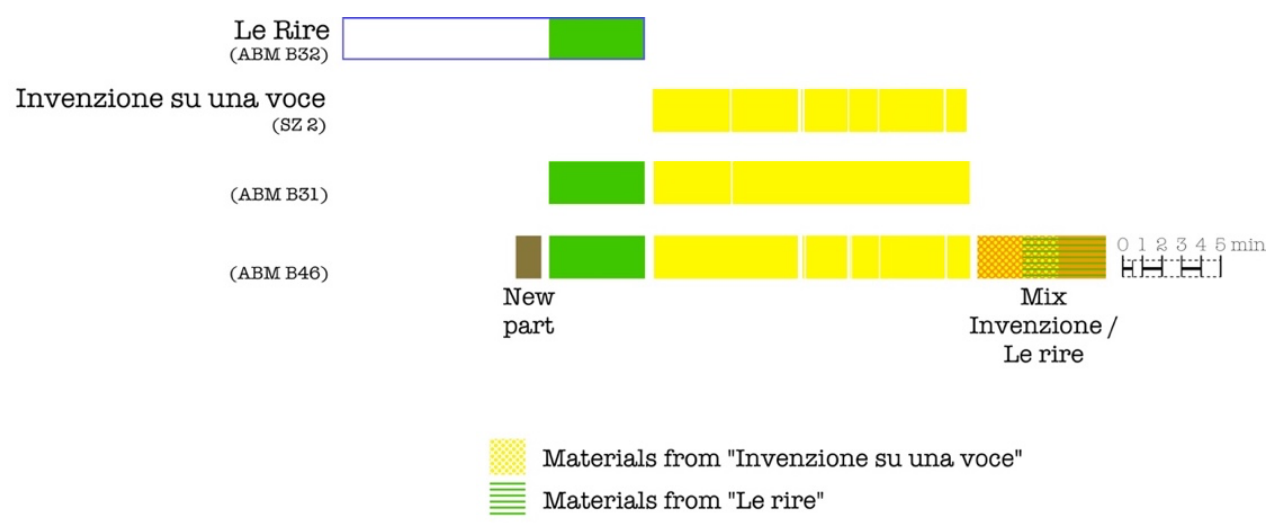

Fig. 4. Hyperion ('Italian' versions). ABM b31: 18-19 July 1968, Feste Musicali in Bologna; ABM b46: 6 September 1964, La Biennale in Venice 1964.

Let's take a closer look at Hyperion en het geweld, based on a libretto from Hugo Claus Morituri (Claus 1968) and premiered in 1968 (17/05) in Brussels.

For creating the different versions of Dimesioni II and the electronic parts of the Italian version of Hyperion Maderna used very common editing techniques, some of which are related to traditional variants the scholar can find in literary philology: insertions, deletion, substitution; other are typical of electronic music: mixing and live recording. Instead, in Hyperion en het geweld it is possible to observe a more elaborate compositional work of recombination of fragments of audio material. An in-depth analysis of the A27 and B35 tapes (figure 5) from the Bruno Maderna Archive in Bologna reveals Maderna's modus operandi. In particular, Le Rire is revised here to become in A27 Introduzione (as in the previous version of the work) and the section called Le Rire. The latter, as usual, keeps the same name as the original work. But unlike Dimension II / Invenzione su una voce, Le Rire is fragmented and transfigured in the recombination of its parts and in the contamination with material that cannot be found in the original work. Its original realization undergoes a deep splicing elaboration: after a section where the fragments are reassembled in the same order of the original work, interpolated with materials taken from other recordings including Musica su due dimensioni 1958, Maderna begins a meticulous work of permutation of 
the order of the parts; finally, he closes the section with a coda containing recordings of orchestral music.

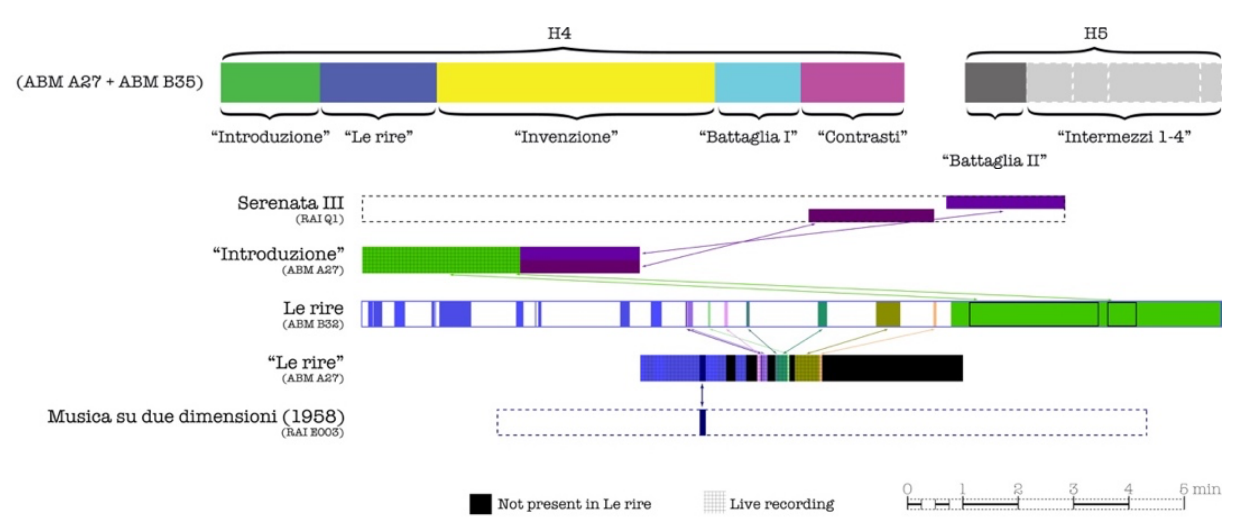

Fig. 5. Hyperion en het geweld (1st version). Above: structure; below: audio materials from Le Rire, Serenata III and Musica su due dimensioni.

In the Introduzione section, the elaborations are simple. Maderna recreates the mix used for the staging in Venice and for the ones in in Bologna using the recording of a live performance of Le Rire held in 1966 in Darmstadt where a flute player, Severino Gazzelloni, dialogues with the electronic part. The audio signal is therefore naturally reverberated (figures 6 and 7).

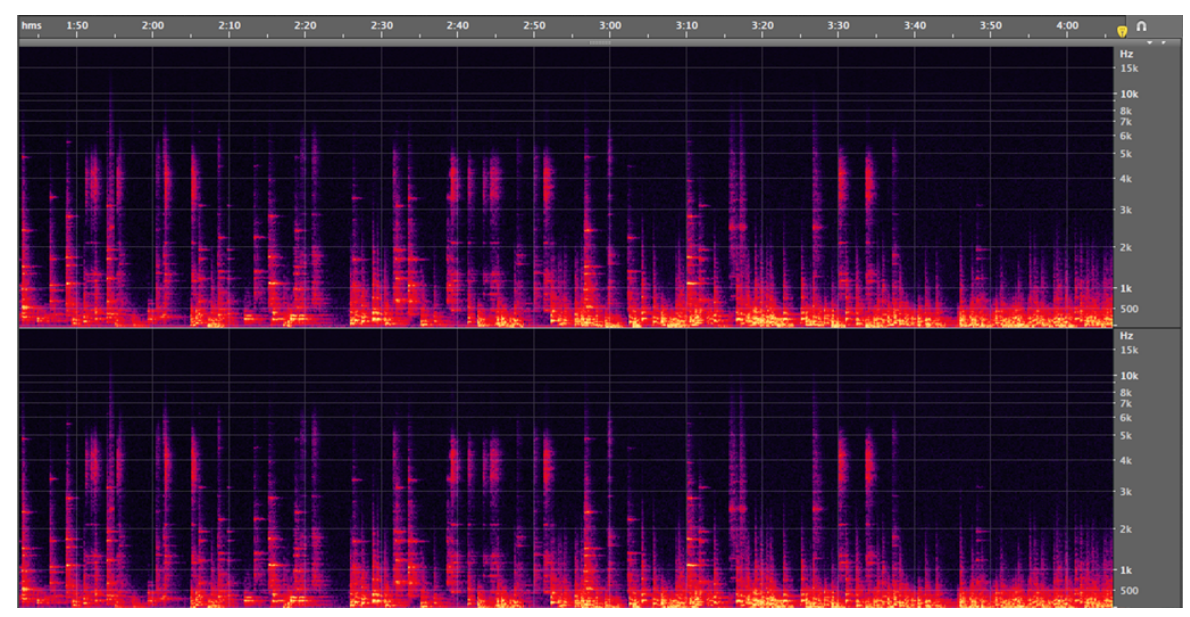

Fig. 6. Introduzione in ABM b46. Window: blackmann-harris, 2048 points, $132 \mathrm{db}$ dynamic range. 




Fig. 7. Introduzione in ABM a27. Window: blackmann-harris, 2048 points, $132 \mathrm{db}$ dynamic range. White: live flute part.

The elaborations are limited to the deletion of sound material and to the interpolation of orchestral parts. At the end of Introduzione, we find a montage of sounds that appear, there reverberated, even in the quadraphonic tape of Serenata III, mixed and redistributed in the stereophonic space.

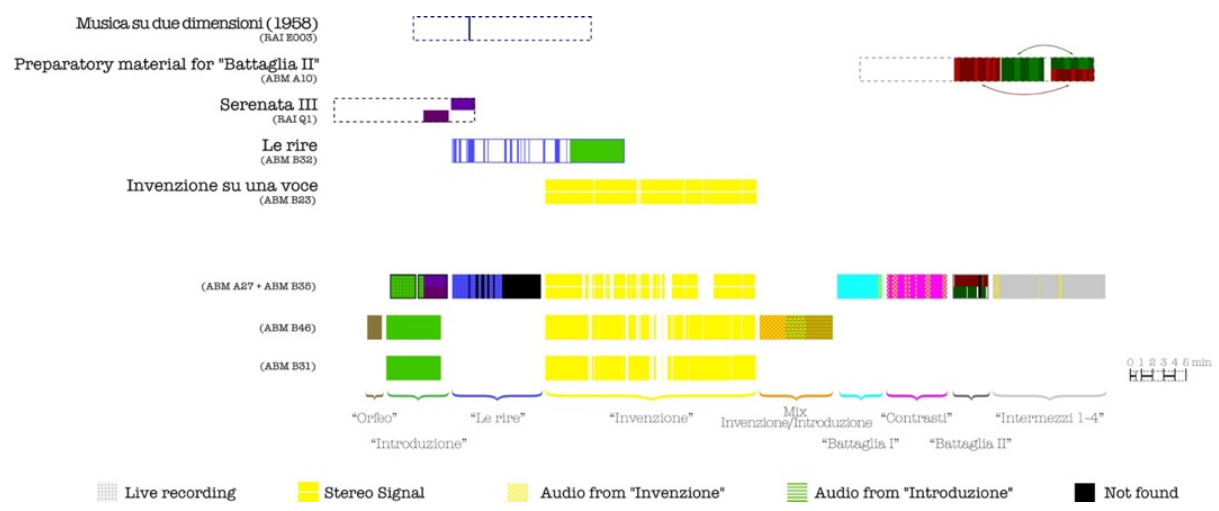

Fig. 8. Hyperion in ABM a27+b35, ABM b46 and ABM b31. Materials from: Dimensioni II/invenzione su una voce (ABM b23), Le Rire (ABM b32), Serenata III (rai q1), Musica su due dimensioni 1958 (RAI e0003) and preliminary materials for Battaglia II (ABM a10).

Figure 8 summarizes the structure of Hyperion as found in the various sources and shows the connection to Dimensioni II / Invenzione su una voce, 
Le Rire, Serenata III, Musica su due dimensioni 1958 and preliminary audio materials (tape A10).

The recombination techniques of the material are finally brought to an extreme degree of complexity in the A22 tape kept by the Bruno Maderna Archive. Here the elaborations reflect a general rethinking of the structure of the work. In the case of the tape the sections have new names (figure 10).

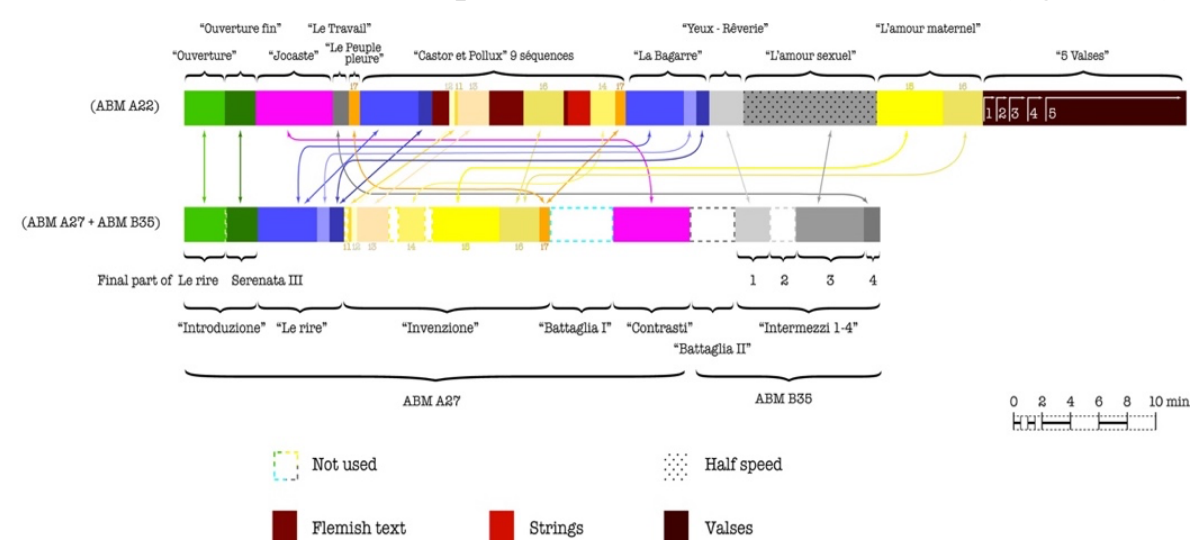

Fig. 9. Hyperion en het geweld (2nd version). Electronic parts in ABM a22. Comparison with $\mathrm{ABM}$ a27 and ABM b35.

As can be seen from the analysis in figure 9, we can find much of the material in the documents already analyzed. Here Dimensioni II/Invenzione su una voce is 'torn apart' and recombined into A22 by procedures similar to those previously adopted for Le Rire. In the permutation of the order of appearance of the individual parts and in their redistribution at different points of the montage, the original identity of the work eventually disappears completely. Here, the deconstruction of Dimensioni II/Invenzione su una voce reflects the changes in Hyperion's dramatic choices: if in the other versions of the work - more faithful to the Hölderlinian themes, including the ones played in Bologna interpolated by Domenico Belli's Orfeo - the 'intrusion' of electronics indicated the breakthrough of technology in the poetic sphere of humankind, in the new version of the work the sources of inspiration are of different content and tenor. The parts sung and spoken in Flemish, drawn from Hugo Claus's Morituri play, are of paramount importance: allusion to the Vietnam War, at the atrocities of military life are frequent and Maderna 
musically evokes the soundscape of the jungle, nightmares of soldiers, and war noises. The introduction of the five Valses, echoing the sonorities of Bertolt Brecht and Kurt Weill, further shows a change in the aesthetic perspective of the work (for further details please refer to Cossettini \& Orcalli 2015).

\subsection{Digital representations of source criticism - A glimpse}

In the interconnection era it is possible to think to systems able to represent the complexity of such compositional practices. Music is first of all a technological phenomenon born from the interdependence of material instruments and musical gestures. The evolution of music is characterized by important feedback and feedforward mechanisms that relate social actors to their cultural and technological context. Dimensioni II / Invenzione su una voce is an emblematic case of this interaction. The tradition of this work can easily be represented with a graph (see Trudeau 1994). First of all, we assume two types of nodes, labeled 'documents' and 'sections' respectively. 
De Musica, 2021 - XXV (1)

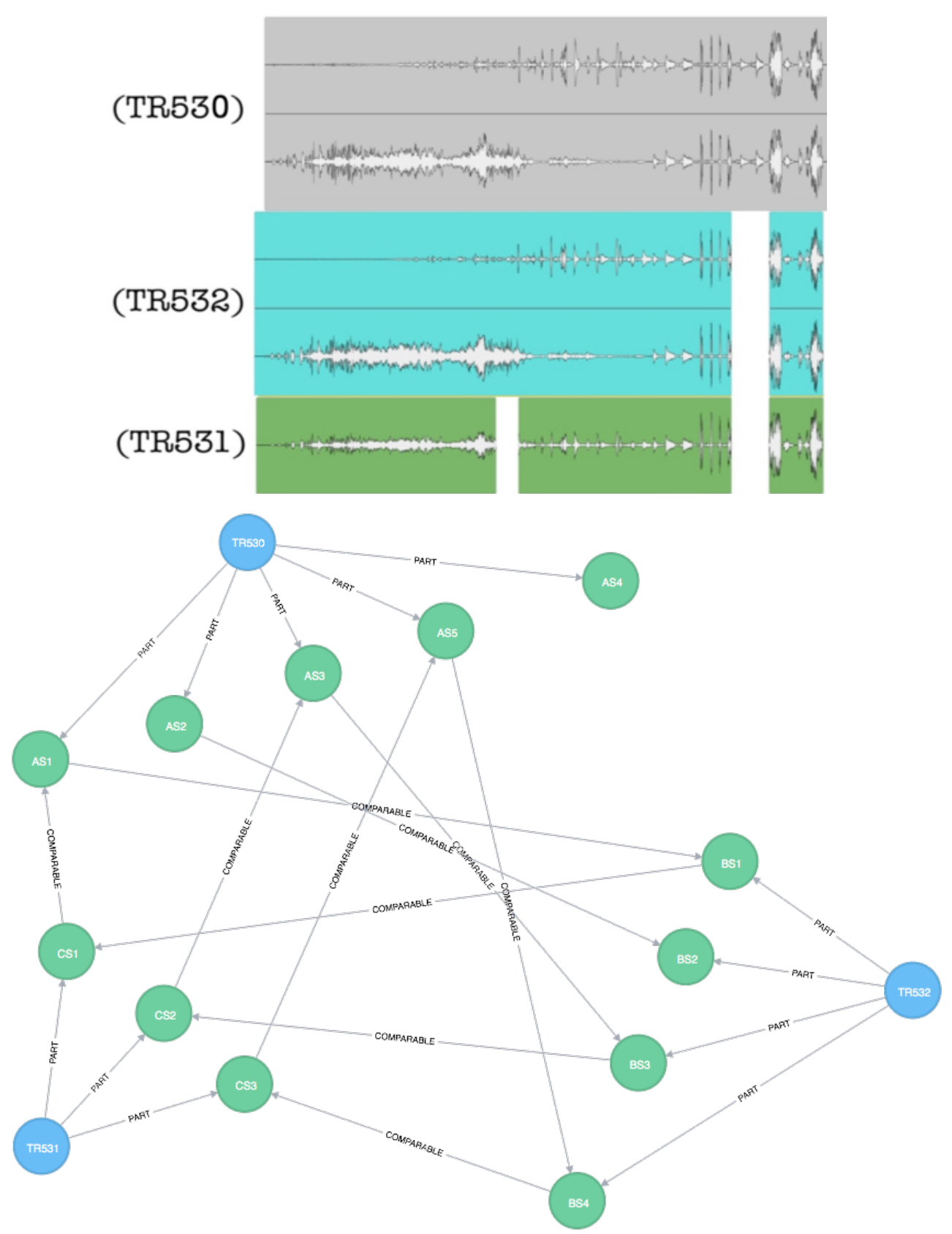

Fig. 10. An excerpt of the comparison among 3 sources of Dimensioni II/Invenzione su una voce and its representation in a graph.

Figure 10 shows the representation of a traditional positive critical apparatus: all the material of the variants is documented, as can be deduced from a segmentation and comparison work. Arcs labeled 'part' link the segments to the document they belong to; arcs labeled 'comparable' relate the segments that are comparable to each other (arcs can be drawn between 
sections belonging to different documents, but also between sections of the same document, in case of reuse of material).

At this point, in terms of IT implementation, this graph can also be formalized with a traditional relational database model. And, in fact, it presents all the limits associated with this technology:

- the need to atomize information makes scalability very difficult: the discovery of a new variant, for example, implies the resegmentation of the entire database;

- the need to hierarchize entities: from the supra-category 'document' descend one or more sub-categories 'section', and this is not always true in the case of the tradition of electronic music (just think to the mixing procedures);

- $\quad$ the need to insert all the data and metadata in the 'document' and 'section' entities with the consequent need to define a priori property schemes (XML schemas, for example).

A more optimized graph modelling - that could be implemented only in a graph database system (see Robinson, Webber \& Eifrem 2015) - can overcome the aforementioned problems, because it is able to manage information, not necessarily pre-determined by schemas, in the arcs as well as in the nodes. 


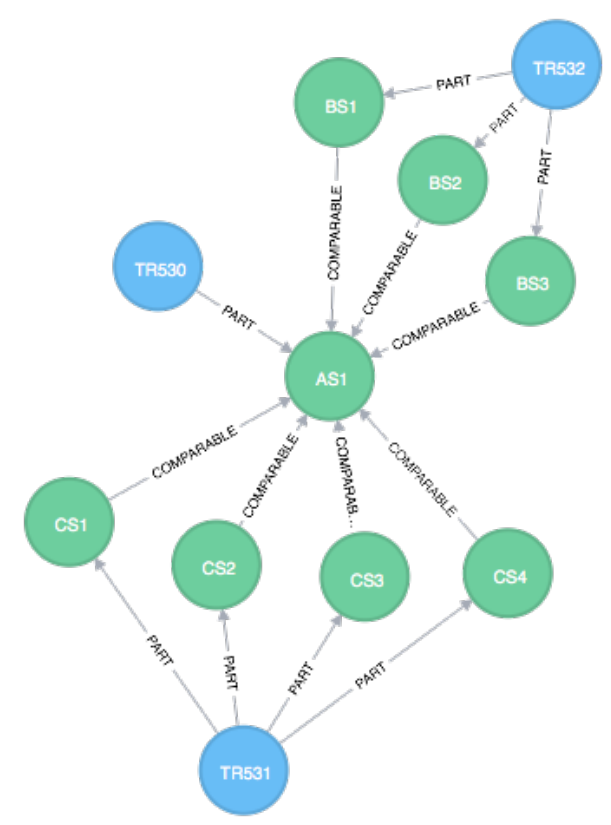

Fig. 11. Optimized graph representation for example in figure 9.

Figure 11 represents the same example as above. The elimination of redundancy and hyper-segmentation is here achieved by inserting the comparability conditions in the 'comparable' arcs: in our case they are simply the starting end the ending points of the comparable parts (eg. the section BS1 is comparable to the section AS1 if the latter is read from the second 0 to the second 120, the section BS2 is comparable to the section AS1 from the second 140 to the second 200, and so on). Note that the arcs that connect the comparable sections of TR532 and TR531 become superfluous: to obtain this information one can simply query the database and find out what the conditions of comparability with AS1 are.

Since neither the hierarchical constraint of the nodes nor pre-established properties schemes exist, it is also possible to represent any type of technical in-depth analysis by adding other conditions of comparability in the arcs. In the case of a mixage, for example, one can connect the 'section' node to multiple 'document' nodes, describing the editing operation by inserting information about volume, equalization, effects, etc. The advantages are not limited to the possibility of representing complex traditions, but also involve the ways how the database is used: the initial questions that the user poses to 
the database - which are the comparable segments? When did Maderna adopted a particular elaboration? Have the same materials been reused in several works? - determine the 'path' within the graph. In this way we rediscover that element of narrativity (and interpretation), typical of every historical investigation, that was canceled by the static nature of information schemas and the pre-established queries of relational databases. This is a clear example on how the web technologies (e.g. HTML5) can be exploited by musicologists and performers for publishing and re-staging also historical electronic music.

\section{The myriad strains, or the eternal transcription}

Romitelli, Risset, Maderna and many others - as well as nowadays composers - spent a part of their compositional efforts in creating libraries and archives of sounds and sound generating procedures. The differences in their nature and the different ways in which authors have used them are related to the specificities of the medium available at the time. Analog electronics on tape, especially, allowed for the addition of a new voice, which however did not have the same immediate variability as a live voice; nevertheless, the electronic medium made it possible to act on the communication process. Maderna fully understood the possibility of getting rid of other performers and their mediation role between musical idea and audience. Through electronics he fixed the interpretation of the work, that is to say sound itself: one and only one among the infinite possible outputs of a complex and nondeterministic human and technological system, constituted by the live relationships among analogical equipment, compositional thought and performing act (see Cossettini 2013). Once recorded on tape, however, sound - using the technological means available at that time - cannot be instantaneously changed. Therefore, if composers also wanted to be performers, in order to renew the interpretation act in each performance, they could use studio manipulation, editing, mixing and copying processes, and 
produce new recordings. This is Maderna's approach to electronics: restating, also in the new media context, that the ultimate purpose of music, its essence, consists in the possibility of recreating it by performing with and whitin technology.

In an interview with Aldo Maranca in 1965, Maderna outlined the general characters of the production process of electronic music in a studio. The composition is expressly regarded here in the same way as an interpretation act:

even if there is a direct relationship between the thought of the work of art and its realization, this relationship always has a passage [...]. A passage that is interpretation. [...] It seems to me that in painting and in literature there is the same passage that happens more or less in the relationship between composer and electronic music. There is a first stage of realization of content and material, then there is an arrangement of the material, i.e. a form that is given to this material; a part of this work can almost be attributed to an interpretative act of the form. [...] It seems that at some point in his work, the composer, the poet or the painter, pass to an interpretation act, to an interpretative representation of his own thought; and this would be the final form (Sani 1995, p. 68 - my translation).

These words bring to mind what Ferruccio Busoni wrote in 1910 in his Sketch of a new esthetic of music where he stated that:

the performance of a work is also a transcription, and still, whatever liberties it may take, it can never annihilate the original. For the musical art-work exists, before its tones resound and after they die away, complete and intact. It exists both within and outside of time, and through its nature we can obtain a definite conception of the otherwise intangible notion of the Ideality of Time (Busoni 1907, p. 18). 
And also:

The myriad strains that once shall sound have existed since the beginning, ready, afloat in the æther, and together with them other myriads that shall never be heard. Only stretch forth your hands, and ye shall grasp a blossom, a breath of the sea-breeze, a sunbeam; avoid routine, for it strives to grasp only that wherewith your four walls are filled, and the same over and over again; the spirit of ease so infects you, that you will scarcely leave your armchairs, and will lay hold only of what is nearest to hand. And myriad strains are there since the beginning, still waiting for manifestation! (Busoni 1907, p. 42).

Maderna, Risset, Romitelli and many other composers have showed us these new 'melodies', they adapted them to the technological system in which they were working at their time, they have given us innumerable interpretations/transcriptions. The study of sources gives us information about their modus operandi in the music laboratory. Having abandoned the idea of 'unified' and 'standardized' work, and embraced the vision of a wonderful multiplicity to which composers themselves have hinted, would it then not be possible think of 'restarting the systems' also without their authors? Or, maybe better, to start new technological systems in the web era and create new 'transcriptions' of the works based on the materials which the composers have left us?

In conclusion, we can make temporal short-circuit and go back to DJ Spooky. In the same interview quoted in the opening of this paper he also stated out that:

The content, the form, all are variables. There's nothing fixed. Everything is completely open to revision and change. It's more accepting of the flow of life as we live it. If I hate an essay, ten years later I might keep one version of it just to remember how I used to do it, but I'll change it. The same thing happens when they reissue the 
Beatles - they'll remaster or digitally edit it. In this culture, we have less and less veneration of primary sources as stable, static things-unless there's an aura of history. It's why the members of the Frankfurt School were up in arms against Americana - they thought it would be a turbulent explosion of impermanence. European intellectuals thought American stuff was always about the next trend and the next and the next (Becker, Crawford \& Miller 2008, p. 85).

But it was not a prerogative of American culture; at least not in music. Music creation in the web era may seem a revolution at first glance. However, a closer look reveals ancient roots in the history of music that audio reproduction has made only more evident: the fixation of music on tape, at first, has brought some composers to create sound libraries to be reused in different works, thus blurring the borders of the musical work; later on, the dematerialization and the atomization of the procedures in IT have pushed towards the 'sharing' - exalted today by the capillarity of the lightning-fast web distribution - raising deep questions about the concept of author itself. But moving back centuries, to the re-uses in Rossini and Mozart, or to the anonymous Gregorian Chant formulas, just to give only a few emblematic examples (the practice of re-use of musical materials is widely discussed in Bertinetto, Gamba \& Sisto 2014), could we not glimpse the recurrence of a quest for a world of «myriad strains that once shall sound», where the composer can stretch forth a hand for a musical idea, wonderfully glimpsed by Busoni in his Sketch for a New Esthetic of Music?

\section{References}

BECKER C., CRAWFORD R, MILLER P. D (2002), An Interview with Paul D. Miller a.k.a. Dj Spooky-That Subliminal Kid, «Art Journal», 61, 1, p. 82-91.

BERTINETTO A. GAMBA E., SISTO D. (eds.) (2014), “Ladri di musica. Filosofia, musica e plagio".+, «Estetica. Studi e ricerche $»$, IV, 1. 
BROWN O., BRITTON S. (2014), An Album in 1,000 Variations: Notes on the Composition and Distribution of a Parametric Musical Work, «Leonardo», 47, 5, pp. 437-441.

BUSONI F. (1907), Entwurf einer neuen Ästhetik der Tonkunst, Im ImfelVerlag, Leipzig (Eng. transl. by T. Baker, G. Schirmer, New York, 1911). CLAUS H. (1968), Morituri, De Bezige Bij, Amsterdam.

COSSETTINI L. (2013), Opere chiuse in sistemi aperti. Autopoiesi nella musica elettronica, Lim, Lucca.

COSSETTINI L., ORCALLI A. (2015), L'invenzione della fonologia musicale, Lim, Lucca.

DANNENBERG R. B., GOLD, N. E., LIANG, D., XIA, G. (2014), Methods and Prospects for Human-Computer Performance of Popular Music, «Computer Music Journal», 38, 2, pp. 36- 50.

ERICKSON R. (1975), Sound Structure in Music, University of California Press, Berkley.

DELFINO P. (2017), La pratique du sampling dans les musiques populaires urbaines, in A. Arbo P.-E. Lephay (eds.), Quand l'enregistrement change la musique, Hermann, Paris, pp. 131-152.

ECO U. (1989), The open work, Harvard University press, Cambridge,

GATHER J. P. (1995), Amsterdam Catalog of Csound Computer Instruments, http://www.codemist.co.uk/AmsterdamCatalog/ (Accessed: February 2., 2021).

MONTANO E. (2010), "How do you know he's not playing Pac-Man while he's supposed to be DJing? ": technology, formats and the digital future of DJ culture, «Popular Music», 29, 3, pp. 397-416.

MURAIL T. (2004), Modèles \& Artifices, textes réunis par Pierre Michel, Presses universitaires de Strasbourg, Strasbourg.

OLTO A. (2017a), EnTrance. Spettralismo e composizione assistita all'elaboratore in Fausto Romitelli, Ph.D. thesis at the University of Udine. 
ID. (2017b), Between spectrum and musical discourse Computer Assisted Composition and new musical thoughts in EnTrance by Fausto Romitelli, in L. Cossettini, A. Orcalli (eds.), Sounds, voices and codes. The critical editing of music at MIRAGE, MIRAGE, Udine, pp. 420-452.

RISSET J.-C. (1969; 2018), My 1969 Sound Catalogue: Looking back from 1992 (1992), in O. Class, M. Grabócz (éds), Jean-Claude Risset. Écrits/writings volume II. Le numérique, un nouvel artisanat pour la création musicale. Outils et æuvres musicales, Hermann, Paris, pp. 331340.

RISSET J.-C. (1992; 2018), An introductory catalogue of computer synthesized sounds (1969), in O. Class, M. Grabócz (éds), Jean-Claude Risset. Écrits/writings volume II. Le numérique, un nouvel artisanat pour la création musicale. Outils et œuvres musicales, Hermann, Paris, pp. 327330.

ROBINSON I., WEBBER J., EIFREM E. (2015), Graph Databases: New Opportunities for Connected Data, O’Rilley, Sebastopol.

SANI N. (1995), Musica elettronica, poetica, scrittura: un colloquio inedito con Bruno Maderna. Musica/Realtà, 45, p. 65-77.

TRUDEAU R. J. (1994), Introduction to graph theory, Dover, Mineola-New York. 